\title{
APUNTES SOBRE LA RESPONSABILIDAD CIVIL DERIVADA DE DESPIDO INCAUSADO O FRAUDULENTO EN EL SISTEMA PERUANO: LA RETÓRICA DE LOS PUNITIVE DAMAGES Y LA DESNATURALIZACIÓN DEL LUCRO CESANTE
}

NOTES ON THE LIABILITY DERIVED FROM WRONGFUL DISMISSAL OR DISMISSAL CONDUCTED IN BAD FAITH WITHIN THE PERUVIAN LEGAL SYSTEM: THE RHETORIC OF PUNITIVE DAMAGES AND THE DENATURALIZATION OF LUCRUM CESSANS

\author{
Héctor Campos García* \\ Pontificia Universidad Católica del Perú \\ Linares Abogados
}

\begin{abstract}
The peruvian Supreme Court has considered at the $V$ Labour Plenary that the remunerations left to be received in cases of uncaused or fraudulent dismissal have a compensatory nature. This interpretation has led the notion of punitive damages to be used rhetorically and has provoced that differentiated rules are established without justification in relation to void dismissal.
\end{abstract}

The article explains the reasons why the Supreme Court assumed such position and criticizes those reasons. Finally, a possible solution is presented so that the magistrates do not apply the refered interpretarion in specific cases.

KEY WORDS: tort law; contract law; punitive damages; lost profit; incause dismissal; fraudulent dismissal; void dismissal.
La Corte Suprema peruana ha considerado en el $\checkmark$ Pleno Jurisdiccional Laboral que las remuneraciones dejadas de percibir en los casos de despido incausado o fraudulento tienen naturaleza indemnizatoria, lo cual ha ocasionado que se recurra de forma retórica a la noción del "daño punitivo" y que se fijen reglas diferenciadas sin justificación alguna con relación al despido nulo.

En el artículo se exponen las razones por las cuales la Corte Suprema asumió tal posición y se formula una crítica a la misma. Finalmente, se expone una propuesta de solución para que los magistrados no apliquen el V Pleno Laboral en casos concretos.

PALABRAS CLAVE: responsabilidad civi; daño punitivo; indemnización; lucro cesante; despido incausado; despido fraudulento, despido nulo.

\footnotetext{
Abogado. Egresado de la Maestría en Derecho Civil y Comercial por la Universidad Nacional Mayor de San Marcos (UNMSM). Profesor de Derecho Civil en la Facultad de Derecho de la Pontificia Universidad Católica del Perú y en la Facultad de Derecho de la UNMSM. Secretario técnico del grupo de trabajo encargado de revisar y formular mejoras al Código Civil. Miembro de la delegación peruana en el Grupo para la Armonización del Derecho en América Latina (Gadal). Asociado del área de Prevención y Solución de Conflictos de Linares Abogados. Contacto: hcampos@linaresabogados.com.pe
} 


\section{A MODO DE INTRODUCCIÓN}

EI V Pleno Jurisdiccional Laboral (en adelante, el V Pleno) fue realizado el 19 de octubre del 2016 en la ciudad de Lima por los jueces supremos integrantes de las Salas de Derecho Constitucional y Social Permanente, y las Primera y Segunda Sala Transitoria de la Corte Suprema de Justicia de la República. Los acuerdos del mencionado Pleno fueron publicados en el Diario Oficial El Peruano el 04 de agosto de 2017.

Para efectos del presente trabajo resulta de interés el acuerdo tomado por mayoría, referido a la "indemnización y remuneraciones devengadas en los casos de despido fraudulento y despido incausado", en la cual se dispuso lo siguiente:

En los casos de despido incausado y despido fraudulento, el trabajador tiene derecho a demandar la reposición en el empleo, además podrá acumular simultáneamente el pago de la indemnización de los daños y perjuicios sufridos, las que incluyen el daño emergente, lucro cesante y el daño moralta indemnización de daños y perjuicios sustituye cualquier pretensión por remuneraciones devengadas.

El juez valorará los medios probatorios para determinar la existencia de daño, la relación de causalidad con el despido, el factor subjetivo de atribución de responsabilidad, y el cálculo de la suma indemnizatoria, según el petitorio y los hechos; asimismo, en caso se le reconozca al trabajador un monto indemnizatorio por daños y perjuicios, el juez de oficio ordenará pagar una suma por daños punitivos (sic), la misma cuyo monto máximo será equivalente al monto que hubiera correspondido al trabajador aportar al Sistema Privado de Pensiones, Sistema Nacional de Pensiones o cualquier otro régimen previsional que corresponda.

Tal como se puede apreciar, en el marco de un despido incausado o fraudulento, la Corte Suprema sostiene, por un lado, que es procedente la solicitud del pago de una indemnización de daños y perjuicios (que comprende el daño emergente, el lucro cesante y el daño moral) de forma conjunta con la reposición en el centro de trabajo, Ello, dado que las condiciones de la responsabilidad civil son la acreditación del daño, la relación de causalidad y el criterio de imputación subjetivo.

Por otro lado, la Corte Suprema vinculó la indemnización por daños y perjuicios (correspondiente al lucro cesante que le correspondería al trabajador) con las remuneraciones dejadas de percibir por el trabajador. Sobre la base de ello, afirma que es posible que los magistrados impongan a los empleadores la obligación de pagar una suma de dinero a título de "daños punitivos" (sic), en función de lo dejado de aportar por el trabajador al Sistema de Pensiones.

En este escenario, el objetivo de la presente contribución consiste en poner en evidencia cómo un inadecuado manejo de instituciones vinculadas al Derecho Civil en el V Pleno ha determinado que se generen impactos negativos tanto en el Derecho Laboral como en el propio Derecho Civil. Ello, en el marco de la responsabilidad civil derivada de losdespidos incausados o fraudulentos.

Para cumplir con el objetivo mencionado seguiré la siguiente estructura: en primer lugar, expondré de forma panorámica el estado de la cuestión del tratamiento jurídico del despido incausado y fraudulento en el sistema peruano. En segundo lugar, desarrollaré los efectos negativos que el V Pleno conlleva tanto a nivel civil como laboral.En tercer lugar, sistematizaré los argumentos que la Corte Suprema ha dado para considerar que las remuneraciones dejadas de percibir tienen naturaleza indemnizatoria. En cuarto lugar, formularé una crítica aa la forma en la que la Corte Suprema ha vinculado las nociones de remuneración dejada de percibir y lucro cesante. En quinto lugar, propondré una alternativa de solución para que, en casos concretos, se prescinda de la tesis asumida por la Corte Suprema y no se generen los impactos negativos expuestos. Finalmente, estableceré algunas conclusiones de carácter general que resumen los principales lineamientos del presente trabajo.

\section{PREMISA: ESTADO DE LA CUESTIÓN EN EL ORDENAMIENTO PERUANO RESPECTO DEL DESPIDO INCAUSADO Y FRAUDULENTO}

En primer lugar, debo iniciar anotando que junto con el despido nulo ${ }^{1}$ y el despido arbitra-

\footnotetext{
Ley de Productividad y Competitividad Laboral. Artículo $29^{\circ}$.- Es nulo el despido que tenga por motivo:

a) La afiliación a un sindicato o la participación en actividades sindicales;

b) Ser candidato a representante de los trabajadores o actuar o haber actuado en esa calidad;

c) Presentar una queja o participar en un proceso contra el empleador ante las autoridades competentes, salvo que configure la falta grave contemplada en el inciso f) del Artículo $25^{\circ}$;

d) La discriminación por razón de sexo, raza, religión, opinión o idioma;

e) El embarazo, si el despido se produce en cualquier momento del período de gestación o dentro de los 90 (noventa) días posteriores al parto. Se presume que el despido tiene por motivo el embarazo, si el empleador no acredita en
} 
rio $^{2}$, previstos legislativamente, la jurisprudencia del Tribunal Constitucional peruano ha reconocido, en la solución de casos concretos, dos tipos de despidos adicionales (Blancas Bustamante, 2013, pp. 473-553; Arce Ortiz, 2008, pp. 542-549; Neves Mujica, 2015, pp. 227-232) ${ }^{3}$; me refiero al despido incausado ${ }^{4} \mathrm{y}$ al despido fraudulento ${ }^{5}$.

En segundo lugar, y, como consecuencia de lo anterior, la regulación legislativa del despido incausado y fraudulento se encuentra, naturalmente, ausente. Ello ha determinado que sea la Corte Suprema, a través de plenos jurisdiccionales, quien termine integrando la regulación normativa aplicable a aquellos tipos de despido.

En tercer lugar, hay que reparar en la regulación normativa aplicable a cada tipo de despido. Por un lado, el despido nulo genera dos consecuencias a nivel del derecho material (Blancas Bustamante, 2013, pp. 414-446) ${ }^{6}$ : (i) la reposición del trabajador en el centro de labores, con el correspondiente reconocimiento del pago de las remuneraciones devengadas durante todo el tiempo que duró el despido; o, (ii) el pago de una indemnización por los daños y perjuicios ocasionados como consecuencia del despido.

Por el contrario, si bien en el caso del despido incausado y fraudulento, se ha admitido, jurisprudencial- mente, que cabe la reposición del trabajador en el centro de labores (Toledo Toribio, 2012, pp. 4-6) ${ }^{7}$ y aspectos referidos al trámite procesal, como la acumulación de pretensiones (Toledo Toribio, 2015, pp. 209-239), no había una posición uniforme respecto de la procedencia en el pago de las remuneraciones devengadas (Blancas, 2013, pp. 556-561).

Dado el escenario en el que se encontraba el tratamiento de las consecuencias jurídicas materiales derivadas del despido incausado y fraudulento,se consideró como uno de los tópicos a tratarse en el V Pleno el siguiente: determinar si el trabajador que ha sufrido un despido incausado o fraudulento tiene derecho al pago de remuneraciones devengadas por el período no laborado. Mediante Acuerdo Plenario establecido en mayoría, se arribó a la siguiente conclusión: "La indemnización de daños y perjuicios sustituye cualquier pretensión por remuneraciones devengadas. (...)". En específico se indicó lo siguiente:

La ausencia de pago de remuneraciones es un hecho evidente y por tanto un daño cierto, que podría ser calificado como lucro cesante, de manera que el monto de dichas remuneraciones pueda servir como un indicador de cálculo del monto de la indemnización, además de

este caso la existencia de causa justa para despedir. Lo dispuesto en el presente inciso es aplicable siempre que el empleador hubiere sido notificado documentalmente del embarazo en forma previo al despido y no enerva la facultad del empleador de despedir por causa justa.

2 Ley de Productividad y Competitividad Laboral. Artículo $34^{\circ}$.- El despido del trabajador fundado en causas relacionadas con su conducta o su capacidad no da lugar a indemnización.

al reconocer como requisitos de la reposición del trabajador a los siguientes: reincorporación en el trabajo sin afectar su categoría anterior, el mantenimiento de su nivel remunerativo, el pago de remuneraciones devengadas y el reconocimiento del tiempo de servicios y depósitos de la compensación por tiempos de servicios.

En los casos de despido nulo, si se declara fundada la demanda el trabajador será repuesto en su empleo, salvo que, en ejecución de sentencia, opte por la indemnización establecida en el rtículo $38^{\circ}$.

3 Para una revisión en perspectiva histórica en el Perú es de consulta Luis Vinatea Recoba (1994, pp. 79-84).

4 De conformidad con la Senetencia del Tribunal Costitucional (en adelante, "STC") recaída en el expediete 976-2001-AA/ TC, se señaló que en el despido incausado: “(...) se despide al trabajador, ya sea de manera verbal o mediante comunicación escrita, sin expresarle causa alguna derivada de la conducta o la labor que la justifique” (p. 15, b).

5 En la STC recaída en el expediente 976-2001-AA/TC, se señaló que en el despido fraudulento: "Se despide al trabajador con ánimo perverso y auspiciado por el engaño por ende, de manera contraria a la verdad y rectitud de las relaciones laborales; aún cuando se cumple con la imputación de una causa y los cánones procedimentales, como sucede cuando se imputa al trabajador hechos notoriamente inexistentes, falsos o imaginarios o, asimismo, se le atribuye una falta no prevista legalmente, vulnerando el principio de tipicidad (...) o se produce la extinción de la relación laboral con vicio de voluntad (...) o mediante la fabricación de pruebas" (p. 15 c)?.

6 En las referidas páginas, Blancas expone con detalle la "eficacia reparadora" del despido nulo al reconocer como requisitos de la reposición del trabajador a los siguientes: reincorporación en el trabajo sin afectar su categoría anterior, el mantenimiento de su nivel remunerativo, el pago de remuneraciones devengadas y el reconocimiento del tiempo de servicios y depósitos de la compensación por tiempos de servicios.

$7 \quad$ En el I Pleno Jurisdiccional Supremo en materia Laboral, de fecha 4 y 14 de mayo de 2012, se acordó que: “Los jueces de trabajo en los procesos laborales (...) están facultados para conocer los procesos de impugnación o nulidad de despido incausado o despido fraudulento, que de ser fundado tengan como consecuencia la reposición del trabajador al centro de trabajo".

8 Nuevamente, nos brinda un panorama respecto de las diferentes posiciones sobre el particular e identifica tres momentos: (i) la posición contraria al pago de remuneraciones devengadas en la jurisprudencia constitucional; (ii) la posición favorable al pago de las remuneraciones devengadas en el criterio de la Corte Suprema; y, (iii) la variación de posición en la jurisprudencia de la Corte Suprema hacia la negativa del pago de las remuneraciones devengadas. 
otros conceptos y montos que el trabajador invoque como daños sufridos como consecuencia del despido (Acuerdo Plenario, 2019).

Desde mi punto de vista, la vinculación entre las remuneraciones devengadas y la indemnización de daños, en específico con relación al lucro cesante, ha originado serias distorsiones a nivel de la determinación del alcance de la indemnización para estas situaciones, y del tratamiento jurídico que reciben los diferentes tipos de despido previstos en nuestro sistema jurídico.

Dedicaré la siguiente sección a explicar los impactos negativos de la posición de la Corte Suprema asumida en el V Pleno.

\section{EL IMPACTO NEGATIVO DEL V PLENO EN EL ALCANCE DE LA INDEMNIZACIÓN Y EN LA TIPOLOGÍA DE DESPIDOS}

Los plenosjurisdiccionales, de conformidad con lo establecido en el artículo 116 del Texto Único Ordenado de la Ley Orgánica del Poder Judicial ${ }^{9}$, tienen como finalidad "concordar jurisprudencia de su especialidad", mas sus acuerdos no son de observancia obligatoria para los jueces de la magistratura peruana, ya que tal condición no le ha sido conferida legislativamente.

Al margen dela finalidad que tienen los plenos jurisdiccionales, considero que, en específico, el V Pleno ha generado distorsiones tanto a nivel civil como a nivel laboral, incorporando una referencia a los "daños punitivos" (sic), cuando los mismos no tienen una previsión en una disposición normativa expresa establecida por el legislador. Asimismo, el $\checkmark$ Pleno ha creado distorsiones funcionales entre los diversos tipos de despidos que afectan, incluso, al sistema previsional peruano. A continuación, desarrollaré cada uno de los impactos negativos que ha producido la emisión del $\mathrm{V}$ Pleno.
A. Primer impacto negativo: el "daño punitivo" (sic) como expediente retórico para afrontar la falta de pago de aportes al sistema de pensiones en el despido (incausado y fraudulento)

Al afirmar que las remuneraciones devengadas pueden ser consideradas como el lucro cesante derivado de despido incausado o fraudulento, la Corte Suprema generó un primer impacto negativo: si se considera que los ingresos dejados de percibir tienen naturaleza indemnizatoria y no contraprestativa, estos no podrán servir de base para el descuento de los aportes que corresponden al sistema de pensiones, ${ }^{10}$ el cual debe realizar el empleador.

Los aportes al sistema de pensiones equivalen a un porcentaje ( $13 \%$ en el sistema nacional y $12 \%$, en promedio, en el sistema privado) que se descuenta del ingreso recibido por el trabajador (dependiente o independiente), y es destinado, según la elección realizada por este, al Sistema Privado de Pensiones (en adelante, SPP) (Rojas, 2014, pp. 105-190) o al Sistema Nacional de Pensiones (en adelante, SNP). Este descuento tiene la finalidad de que, al momento de la jubilación del trabajador, este cuente con una pensión fija que le sirva de sustento.

Si las remuneraciones devengadas se pagan al trabajador a título de resarcimiento y no a título contraprestativo, tal como ha indicado el V Pleno con relación a los casos de despido incausado o fraudulento, entonces, durante todo el tiempo que media entre el despido y la reposición, se generan dos situaciones que deben ser advertidas. Por un lado, el trabajador se verá privado del beneficio que le produce la aportación al sistema previsional $^{11}$ (a menos que decida realizar un aporte voluntario); y, por otro lado, el sistema de pensiones no recibirá los aportes respectivos, agravando con ello la sostenibilidad, de por lo menos, el SNP.

\footnotetext{
TUO Ley Orgánica del Poder Judicial.
}

Artículo 116.- "Los integrantes de las Salas Especializadas, pueden reunirse en plenos jurisdiccionales nacionales, regionales o distritales a fin de concordar jurisprudencia de su especialidad a instancia de los órganos de apoyo del Poder Judicial".

10 Para una referencia de los antecedentes del sistema de pensiones, puede revisarse el trabajo de Javier Neves (1993, pp. 7-10)

11 Esta, en concreto, fue la motivación que llevó a los Señores Jueces Supremos Titulares Walde Jáuregui y Rodriguez Mendoza,así como al Juez Supremo Provisional Toledo Toribio a emitir un voto en minoría, en el V Pleno, en el que se inclinaban por reconocer las remuneraciones devengadas en los despidos incausados y fraudulentos justificado en lo siguiente: "Declarar que el trabajador sólo tiene derecho a la indemnización por daños y perjuicios con ocasión de un despido incausado o fraudulento haría inviable la posibilidad de que el trabajador pueda acumular su tiempo de servicios, sus beneficios sociales y la posibilidad de que el empleador, al ser condenado al pago de las remuneraciones dejadas de percibir, tenga que efectuar las aportaciones de carácter previsional, aspectos que serían jurídicamente inviables solicitarlos vía indemnización por daños y perjuicios”. Cabe resaltar que, adicionalmente, los magistrados invocaron la decisión de la Corte Interamericana de Derecho Humanos en el caso Aguirre Roca, Rey Terry y Revoredo Marsano versus Perú, en la Sentencia de fecha 31 de enero de 2001, en la que se reconoció la obligación del Estado de pagar los montos correspondientes a los salarios caídos y demás derechos laborales que correspondan a los magistrados destituidos, de acuerdo con la legislación peruana. 
Planteada la problemática en los términos indicados, derivados del hecho que la Corte Suprema determinó que las remuneraciones dejadas de percibir se pagan a título resarcitorio, deviene la necesidad, para los magistrados supremos que participaron del $\checkmark$ Pleno, de establecer una propuesta de solución.

Dicha propuesta implicaba identificar un mecanismo a través del cual: (i) se garantice que el trabajador no pierda el beneficio de los aportes al sistema previsional durante el período en el que la relación laboral haya sido suspendida de forma ilegítima por el despido incausado o fraudulento; $y$, al mismo tiempo, (ii) se garantice que el sistema previsional reciba directamente los aportes devengados por el período en que el despido incausado o fraudulento produjo sus efectos. Es decir, desde el despido hasta la reposición.

Nótese que si no se hubiese realizado un intento por buscar una solución a la problemática planteada, se habría generado una diferenciación absurda y arbitraria ${ }^{12}$ entre los diferentes tipos de despido. Ello, debido a que ante una pluralidad de despidos injustificados, solo en un despido nulo (y no en el incausado o fraudulento) se le permitía al trabajador gozar, no solo de sus remuneraciones devengadas, sino que también, como consecuencia de ello, de los beneficios que conllevan los aportes al sistema de pensiones correspondiente, que, si bien debían ser efectuados por el empleador, son de cargo del trabajador, por lo que se deducen de su remuneración.

En este contexto, ¿cuál fue la solución que empleó la Corte Suprema para enfrentar tal problemática? Pues, simple y llanamente, recurrió a la posibili- dad de reconocer que, de forma adicional a la indemnización compensatoria derivada del despido incausado o fraudulento (que comprende el daño emergente, el lucro cesante y el daño moral), es procedente el pago de "daños punitivos"13 (sic) a favor del trabajador, los cuales serían calculados en su monto máximo -según lo indicado por el $\mathrm{V}$ Pleno- en una "suma equivalente al monto dejado de aportar por el trabajador, sea al Sistema Privado de Pensiones, Sistema Nacional de Pensiones o cualquier otro sistema previsional al que esté obligado pertenecer por mandato de ley"14.

La indemnización punitiva ${ }^{15}$ (punitive damages) son sumas de dinero que se imponen al responsable de un daño de forma adicional a la indemnización compensatoria (compensatory damages), en el marco de la protección civil de una situación jurídica, contra la persona que de forma negligente o dolosa ha violado flagrantemente y sin consideración alguna los derechos del demandante (Georgiades, 2005, p. 146); por lo que usualmente se sostiene que la indemnización punitiva tiene dos amplios objetivos sociales; a saber: (i) la disuasión (deterrence); y, (ii) la punición (punishment) (Polinsky y Shavell, 1999, p. 765), aunque no faltan lecturas que reconocen fines de carácter retributivo (Zipursky, 2005, pp. 105-110).

En ese sentido, la Corte Suprema ha recurrido a los "daños punitivos" (sic), no con el objetivo de establecer una medida económica represiva o disuasiva, sino con la exclusiva finalidad de tener un justificativo para conceder al trabajador una suma que pueda ser equivalente al monto dejado de aportar al sistema de pensiones desde el momento en que se produjo el despido hasta que se realizó

12 Esta también fue la preocupación del Señor Juez Supremo Provisional Carlos Giovanni Arias Lazarte, quien al emitir su voto en minoría en el V Pleno indicó lo siguiente: "De desestimarse la petición de remuneraciones devengadas en los casos de despidos fraudulentos e incausados bajo el argumento de que su abono se encuentra reservado sólo para cuando el trabajador impugne el despido mediante la acción de Nulidad de Despido prevista por el artículo $29^{\circ}$ de la LPCL, conllevaría a que frente a hechos iguales (actos lesivos de derechos constitucionales) se estaría otorgando consecuencias jurídicas distintas. Dicha decisión importaría la inobservancia de los previsto por el artículo III del Título Preliminar del Código Procesal Civil, en virtud del cual el Juez está en la obligación de tener presente que la finalidad abstracta del proceso es lograr la paz social en justicia; asimismo, contravendría el principio de igualdad consagrada en el artículo 2.2. de la Norma fundamental que es la norma que mejor protege el derecho del trabajador en el caso planteado: a igual razón, igual derecho".

13 Tal como se puede apreciar, la referencia a los daños punitivos es una traducción mecánica de la voz, propia del law of torts, conocida como punitive damages. Sobre la base de una noción amplia de indemnización, considero que es mejor hacer alusión a indemnización punitiva, ya que lo punitivo no es el daño, sino la indemnización (Campos, 2019, pp. 1-2). Sin embargo, por las razones que se apuntan en el texto, no considero que pueda deducirse de esta sola indicación nominal realizada por la Corte Suprema una conclusión válida respecto de la presencia o viabilidad de la proyección de esta categoría, correctamente entendida y diseñada, en el ordenamiento peruano.

14 Para un comentario al V Pleno, desde una perspectiva laboral, que brinda luces sobre el tratamiento del sistema de pensiones ver a Abanto y Paitán (2017, pp. 33-47).

15 Para un panorama de los punitive damages puede revisarse: Gotanda, 2004, pp. 11-12; Koziol, 2008, pp. 741-764; Benatti, 2017, p. 4; Grondona, 2017, pp. 1-36. En el ordenamiento peruano: De Trazegnies, 1990, pp. 50-62; Fernández Cruz, 2001, pp. 262-268; León Hilario, 2006, pp. 34-35; García, 2018, pp. 162-165. En este extremo, dado que no corresponde con los fines del presente trabajo, solo me limito a anotar que la aplicabilidad de las indemnizaciones punitivas en el ordenamiento peruano debe ser concordante con el principio de tipicidad y legalidad, de modo que el reconocimiento por parte de un Pleno Jurisdiccional representa una manifiesta vulneración al principio de separación de poderes que termina deslegitimando dicha institución (Campos, 2019, pp. 2-3). 
la reposición, que es, precisamente, lo que se le había negado al trabajador una vez que se optó por la tesis según la cual las remuneraciones devengadas se otorgan en calidad de lucro cesante y no con una naturaleza remuneratoria. Desde otra perspectiva, se confirma lo previamente indicado si se toma en cuenta que el criterio que se emplea para cuantificar el "daño puntivo" (lo dejado de aportar al sistema de pensiones desde el momento en que se produjo el despido hasta la efectiva reposición) no tiene (ni puede tener) ninguna vocación represiva o disuasiva, dado que por su baja cuantía no representa un desincentivo respecto de la conducta dañosa (despido incausado o fraudulento) del empleador.

En consecuencia, bien vistas las cosas, la referencia a los "daños punitivos" (sic), antes que un supuesto de importación de una categoría jurídica extranjera o de un "trasplante legal"16, dada su nula vocación punitiva o disuasiva, solo puede considerarse como un mero expediente retórico para solucionar el problema práctico de la falta de aporte al sistema previsional, el cual fue generado por la propia Corte Suprema al establecer su particular entendimiento entre el lucro cesante y la remuneración dejada de percibir.

De este modo, sin que medie ninguna disposición normativa dispuesta por el legislador, la Corte Suprema ha ampliado el ámbito de las indemnizaciones no resarcitorias al reconocer la procedencia de indemnizaciones punitivas, lo cual, evidentemente, implica una intromisión por parte de la función jurisprudencial en la función legislativa, vulnerándose así el principio de separación de poderes y alterando el régimen indemnizatorio en el ordenamiento peruano.

B. Segundo impacto negativo: el injustificado tratamiento diferenciado entre el despido nulo y los despidos incausado y fraudulento. Repercusiones en el sistema previsional

En este apartado mostraré el segundo impacto negativo del $\mathrm{V}$ Pleno, en específico, lo caótico y contradictorio en que se ha convertido el sistema laboral y previsional peruano.

Tal como señalé, las remuneraciones devengadas se pagan a favor del trabajador al ser consideradas como lucro cesante derivado del despido incausa- do o fraudulento. Adicionalmente, el empleador debe pagar, a favor del trabajador, una suma a título de "daño punitivo" (sic), cuyo monto no podrá ser mayor al monto dejado de aportar por el trabajador, sea al SPP, SNP o cualquier otro sistema previsional al que esté obligado pertenecer.

Desde un punto de vista que involucre a las partes de la relación jurídica laboral se han generado dos efectos nocivos. En primer lugar, bajo la nueva interpretacióna, se termina sancionando al empleador de una forma más intensa en el despido incausado que en el despido nulo. Mientras que en este último, el empleador está obligado a pagar el aporte al sistema previsional aplicando un descuento sobre las remuneraciones dejadas de percibir por el trabajador,en los despidos incausados o fraudulentos, el monto equivalente al aporte al sistema de pensiones no se descuenta de ninguna remuneración devengada (ya que solo tiene naturaleza indemnizatoria como lucro cesante), sino que se consigue, directa y adicionalmente, del patrimonio del empleador; afectándose su situación de una manera más gravosa, y paradójica, en comparación con la del despido nulo.

En segundo lugar, ahora, en el despido incausado o fraudulento se tutela de una mejor manera al trabajador a comparación al que es despedido mediante un despido nulo. En efecto, el trabajador despedido incausada o fraudulentamente recibe el íntegro de su remuneración (sin descuento por el aporte previsional) y, adicionalmente, un monto que es (o seguramente será) el equivalente al aporte no realizado al sistema de pensiones, pero que lo recibe directamente, sin que nada sea destinado obligatoriamente al SNP o al SPP.

Esta situación es completamente diferente en el despido nulo, en donde la naturaleza contraprestativa de las remuneraciones devengadas hace que el trabajador solo reciba estas, y respecto de las mismas se aplica el descuento correspondiente al aporte al sistema previsional; con lo cual, el trabajador recibe un tratamiento menos favorable que en el despido incausado o fraudulento. En esta sede conviene el preguntarnos: ¿Existe alguna justificación para que un trabajador despedido por razones de discriminación, por pertenecer a un sindicato o por embarazo, sea menos tutelado respecto de un trabajador despedido por una causa inventada? La respuesta es rotundo no.

16 En este extremo manifiesto mi respetuosa discrepancia ante lo señalado por Luis Bardales (2017, pp. 39-40), cuando indica: "Qué duda cabe de que estamos ante un supuesto de importación de modelos jurídicos foráneos. Este fenómeno, por el cual la judicatura nacional se encuentra constantemente importando doctrinas o instituciones jurídicas de otros sistemas y ahora de otra tradición jurídica, en especial del common law, se ha venido dando ya desde varios años, convirtiéndose el área de la responsabilidad civil en un terreno que ha permitido la alienación del discurso jurídico peruano". Mi discrepancia no radica en que no considere negativa la importación de figuras jurídicas cuando no media el análisis crítico del contexto 
En este panorama, el V Pleno ha logrado establecer una situación, ciertamente caótica: ha colocado al empleador de un despido incausado o fraudulento en una posición más gravosa y al trabajador en una posición más beneficiosa, en comparación a la posición que tienen el empleador y el trabajador de un despido nulo.

En tercer lugar, y derivado de los dos anteriores, inexorablemente se afecta al sistema previsional en su conjunto, pero especialmente, al SNP. Al no garantizar, en el despido incausado o fraudulento, a diferencia del despido nulo, el aporte se destine al sistema previsional se expone al SNP, principalmente, a recrudecer sus dificultades de financiamiento a mediano y largo plazo, en desmedro de todos los beneficiarios del mismo (González Nieve, 2004, pp. 349-387; Abanto Revilla, 2004, pp. 389-403; Gonzáles Hunt, 2013, pp. 600-621).

Si nos encontramos ante diferentes modalidades de despidos que, por ser lesivos para los derechos fundamentales, no generan extinción del vínculo laboral, sino reposición, ¿por qué aplicar un régimen que genera consecuencias nocivas en el ámbito laboral y el previsional? ¿Por qué aplicar un régimen que avala que el despido incausado o fraudulento sea más beneficioso para el trabajador que en un despido nulo? ¿Por qué permitir que el despido incausado o fraudulento sea más oneroso para el empleador que en un despido nulo? No encuentro justificación alguna para ello.

\section{LOS FUNDAMENTOS DE LA CORTE SUPRE- MA PARA CONSIDERAR QUE LAS REMUNE- RACIONES DEVENGADAS NO TIENEN NATU- RALEZA CONTRAPRESTATIVA}

Los efectos negativos del V Pleno que he desarrollado en la sección anterior, conforme indiqué previamente, encuentran su origen en la particular relación que la Corte Suprema ha establecido entre la remuneración dejada de percibir y el concepto indemnizatorio de lucro cesante.
La presente sección está destinada a sistematizar las razones por las cuales el V Pleno concibe que, para el caso del despido incausado o fraudulento, las remuneraciones dejadas de percibir no tienen naturaleza contraprestativa, sino indemnizatoria (lucro cesante), ello con la finalidad de comprender las mismas y atender si tienen fundamento.

A. La posiciónmayoritaria que establece la imposibilidad de reconocer naturaleza contraprestativa a las prestaciones dejadas de percibir: la tesis de la ficción legal

La Corte Suprema, para arribar a su voto en mayoría, toma la siguiente premisa de análisis para determinar si procede el pago de las remuneraciones dejadas de percibir en el despido incausado o fraudulento: la inexistencia de una disposición normativa legal que determine que en estos casos persista la relación laboral o que el trabajador tenga derecho al pago de remuneraciones.

De este modo, se puede apreciar la expresa comparación ( $y$, aparentemente, la necesidad de equiparación) entre el régimen establecido para el despido nulo y las consecuencias jurídicas que le deberían corresponder al despido incausado o fraudulento.

En este punto se debe recordar que en el sistema laboral peruano es procedente el pago de remuneraciones devengadas derivadas del despido nulo, a título contraprestativo, en función del "mandato legal" previsto en el artículo 40 de Ley de Productividad y Competitividad Laboral ${ }^{17}$.

Bajo este panorama, la Corte Suprema aleja la obligación de pagar las retribuciones devengadas en el marco de un despido nulo de cualquier consideración "reintegrativa" vinculada a la ineficacia del acto de despido y las conduce al ámbito estrictamente contraprestativo ${ }^{18}$. Esta decisión se justifica únicamente en el establecimiento de una ficción jurídica creada por el legislador (tesis de la ficción

de origen o de compatibilidad con el ordenamiento receptor de la importación, sino que, en el presente caso, sostener que estamos ante una "importación de un modelo jurídico foráneo" resulta una lectura de buena fe respecto del V Pleno. Y es que atendiendo al contexto (y antecedentes) en el que se ha producido el reconocimiento del "daño punitivo" (sic), no parece ser una importación propiamente de los punitive damages, sino tan solo un (mero) intento de recurrir a un instrumento del cual se valió, incidental y abruptamente la Corte Suprema, para salir del laberinto construido sobre la base de considerar a las remuneraciones devengadas como lucro cesante derivado de despido incausado o fraudulento.

17 Ley de Productividad y Competitividad Laboral. Artículo $40^{\circ}$.- Al declarar fundada la demanda de nulidad de despido, el juez ordenará el pago de las remuneraciones dejadas de percibir desde la fecha en que se produjo, con deducción de los períodos de inactividad procesal no imputables a las partes. Asimismo, ordenará los depósitos correspondientes a la compensación por tiempo de servicios y, de ser el caso, con sus intereses.

18 Esta posición se sustenta en el hecho de que la remuneración es la contraprestación al trabajador por la puesta a disposición de su actividad, salvo los escenarios de suspensión imperfecta de la relación laboral. Así lo explican, entre otros: Ferro, 1998, pp. 14-17; Toyama, 2000, pp. 399-404; Pizarro, 2006, p. 167; Arce, 2008, pp. 328-333; Neves, 2009, pp. 39-40. 
legal), en función de la cual se considera que se ha producido el desarrollo de la labor efectiva de trabajo en el período entre el despido y la reposición.

Vistas así las cosas, la Corte Suprema no podía reconocerle (y no lo hizo) a las prestaciones dejadas de percibir una naturaleza contraprestativa (remunerativa) para el caso de despidos incausados o fraudulentos, ya que ello implicaría extender los efectos de una ficción jurídica, prevista legislativamente para el despido nulo, a otras hipótesis que no cuentan con algún respaldo normativo en ese extremo.

Llegados a este punto, no puedo dejar de llamar la atención respecto del doble discurso que se maneja en el $\mathrm{V}$ Pleno respecto al principio de legalidad. La Corte Suprema no puede mostrarse excesivamente respetuosa del mismo en el ámbito laboral (al no querer aplicar las consecuencias del despido nulo a los despidos incausado o fraudulento por no contar con una habilitación normativa), pero extremadamente ligera en el ámbito civil (al crear sin respaldo normativo alguno una categoría adicional dentro de las indemnizaciones no resarcitorias como lo es la indemnización punitiva). El sesgo interpretativo es manifiesto.

\section{B. La posición minoritaria que reconoce una naturaleza reintegrativa a las prestaciones dejadas de percibir: la tesis de los efectos retroactivos del acto de despido ineficaz}

No obstante lo indicado en el acápite precedente, se debe dejar establecido que en el V Pleno se formuló un discurso alternativo a la tesis de la fic- ción legal que sí permitiría justificar el pago de las prestaciones dejadas de percibir por el trabajador a título remunerativo en los supuestos de despidos incausado y fraudulento.

Una posición en minoría ${ }^{19}$ sugirió que el pago de las remuneraciones devengadas en el despido nulo se justificaría en que aquello es una consecuencia lógica de todo acto que sea considerado como ineficaz (en donde la ineficacia tenga efectos retroactivos).

En otras palabras, esta justificación se basa en la necesidad de "reintegrar" 20 la situación jurídica de las partes afectadas, por dicho acto (ineficaz), a la situación en la que se encontraban al momento previo de su realización, lo cual, en el caso del despido nulo, se manifiesta en considerar que la relación jurídica laboral nunca fue extinguida (Quispe, 2006, pp. 41-45; Blancas Bustamante, 2013, pp. 434-435; Arce Ortiz, 2015, pp. 236-237) ${ }^{21}$.

Bajo esta lógica, el despido incausado o fraudulento es, también, un acto que no puede producir la consecuencia jurídica de extinción del vínculo laboral, por ser lesivo de derechos constitucionales, pudiendo calificarlo como un despido inválido y por ende ineficaz. Entonces no solo se justificaría la reposición al centro laboral, sino que resultaría natural que también proceda el pago de las remuneraciones devengadas, como parte del efecto "reintegrativo" del acto ineficaz (la tesis de los efectos retroactivos del acto de despido ineficaz); todo ello, claro está, en el marco del proceso laboral.

19 Esta fue la posición del juez supremo provisional Carlos Arias Lazarte, quien emitió un voto en minoría en el V Pleno justificando su posición en lo siguiente: "No debe soslayarse que mediante la reposición del trabajador a su puesto de trabajo, en los casos de despidos incausados o fraudulentos, se restablece automáticamente el vínculo laboral como si éste nunca se hubiere interrumpido, pues el acto lesivo sobre el cual ha caído pronunciamiento es el acto mismo del despido, no se crea derecho nuevo alguno en favor del trabajador; en consecuencia, jurídicamente el tiempo transcurrido durante el despido debe ser idéntico al transcurrido antes de él, toda vez que lo contrario significaría vaciar de contenido a la eficacia restitutoria, motivo por el cual la protección al derecho constitucional antes señalado debe efectuarse en toda su extensión, comprendiéndose dentro de él al abono de las remuneraciones devengadas, ya que la parte empleadora, en mérito a acto propio declarado judicialmente inconstitucional, no puede verse favorecida con el no pago de ellas, toda vez que ello con llevaría a que siga manteniendo esa actitud, que, además, tienen un efecto negativo frente a todos los otros empleadores del país".

20 En esta ocasión estoy empleando el término "reintegrar" en una noción amplia, simplemente para significar que como consecuencia del acto ineficaz es posible que se deriven tanto prestaciones de hacer como de no de hacer que permitan colocar a las partes en la situación que estaban antes de que el acto se haya celebrado. No obstante, en doctrina se suele manejar una noción mucho más restringida del término "reintegrar". Para una aproximación a la diferenciación entre la tutela reintegrativa, tutela restitutoria y la tutela reparadora, se puede consultar: Tapia, 2013, pp. 123-153.

21 Así, por ejemplo; Carlos Blancas señala: "En este caso, es decir la nulidad del despido, la falta de prestación de sus servicios por el trabajador, no libera al empleador de cumplir con su contraprestación, como es regla indiscutible en los contratos con prestaciones recíprocas (artículo 1426 del Código Civil), y, entre estos, el contrato de trabajo, toda vez que se considera que el acto extintivo del empleador está viciado de ilegalidad ab origine, por lo que carece de eficacia jurídica para disolver la relación laboral. Por ello, sería incoherente, que la reposición del trabajador no estuviera acompañada del pago de remuneraciones devengadas durante su ausencia"; a su turno Elmer Arce precisa: "Situación ésta que, lógicamente, por lo demás, viene a revelar la naturaleza estrictamente salarial de esta obligación dineraria. En consecuencia, debe quedar claro que los salarios dejados de percibir en el sentido del artículo 40 de Ley de Productividad y Competividad Laboral, no tiene carácter resarcitorio, sino (...) de conceptos salariales vinculados a la declaración de subsistencia del contrato de trabajo en sus propios términos originarios". 
Si bien frente a esto se podría oponer el hecho de que, en tanto la prestación laboral no ha sido efectivamente prestada, no corresponde el pago de la contraprestación, debemos recordar que nos encontramos ante una consecuencia jurídica natural de la ineficacia del acto de despido y no ante la determinación, típicamente conmutativa, de la remuneración, ello sin considerar que la falta de realización de la prestación laboral no obedece a una causa imputable al trabajador.

En efecto, si se atiende a las consecuencias de los actos ineficaces (como lo son aquellos que incurren en una causal de nulidad), en el caso de los despidos incausados o fraudulentos, no era necesario establecer la existencia de una ficción (de la prestación del servicio) para justificar el pago de las remuneraciones devengadas.

Y ello es así, ya que los despidos incausados y fraudulentos son materialmente nulos, y por ende ineficaces. En nada se opone el hecho que no reciban la denominación de "despidos nulos", ya que la nulidad no se determina de forma terminológica, sino por configurarse alguna causal expresa. En este caso, el hecho que los despidos sean lesivos de derechos constitucionales implica la contravención a normas imperativa de orden público o, en todo caso, a las buenas costumbres; lo cual conlleva la calificación material de la nulidad del despido, más allá de que no haya recibido tal denominación por la legislación laboral.

\section{CRÍTICA AL EQUÍVOCO ENTENDIMIENTO DE LA REMUNERACIÓN DEJADA DE PERCIBIR EN EL DESPIDO INCAUSADO O FRAUDULEN- TO COMO LUCRO CESANTE}

Las razones expuestas en la sección anterior muestran cómo es que la Corte Suprema peruana, en el V Pleno, negó la función contraprestativa a las remuneraciones devengadas, lo cual conllevo, en última instancia, a que se le reconozcan una función indemnizatoria, ello a la luz de un particular entendimiento del lucro cesante.

A demostrar que las remuneraciones dejadas de percibir no pueden ser consideradas, bajo una aproximación civilista, y bajo ningún entendimiento técnico, como lucro cesante, está destinada la presente sección.
A. Las remuneraciones devengadas no constituyen el lucro cesante derivado del despido incausado y fraudulento: deslinde conceptual.

El V Pleno ha cometido el palmario error de equiparar las remuneraciones devengadas dejadas de percibir por el período no laborado derivado del despido incausado y fraudulento con la noción de lucro cesante.

En específico, en la justificación del Acuerdo Plenario, se ha indicado lo siguiente:

\begin{abstract}
La ausencia de pago de remuneraciones es un hecho evidente y por tanto un daño cierto, que podría ser calificado como lucro cesante, de manera que el monto de dichas remuneraciones pueda servir como un indicador de cálculo del monto de la indemnización, además de otros conceptos y montos que el trabajador invoque como daños sufridos como consecuencia del despido (Acuerdo Plenario, 2016).
\end{abstract}

Dicha posición, inclusive, había sido asumida en el Pleno Jurisdiccional Nacional Laboral y Procesal Laboral realizado en la ciudad de Chiclayo, los días 13 y 14 de setiembre de 2018, en el que, expresamente en el primer subtema (Indemnización por lucro cesante en caso de despido incausado y fraudulento), se arribó al siguiente acuerdo: “En caso de despido incausado y fraudulento la indemnización por lucro cesante se debe equiparar a las remuneraciones dejadas de percibir" (2018).

En este extremo se debe ser enfático: las remuneraciones dejadas de percibir no constituyen el lucro cesante derivado ni del despido incausado, ni del despido fraudulento, ni de ninguno de los tipos de despidos existentes en la regulación laboral peruana.

La razón de la afirmación precedente es simple: el lucro cesante, conceptualmente, no está constituido por el ingreso dejado de percibir; sino por el rédito o utilidad que, normalmente, ingresaría al patrimonio de la víctima, pero que como consecuencia del daño no se llegará a percibir. Esta idea es pacífica en la doctrina civil peruana (Osterling Parodi, 1968, p. 95; Rey de Castro, 1972, p. 325; De Trazegnies Granda, 1990, p. 37; Taboada Córdova, 2013, p. 73; Espinoza Espinoza, 2016, p. 301, León Hilario, 2016, pp. 60-61; Fernández Cruz, 2017, p. 137) 22.

22 Veamos: Felipe Osterling, expresamente, define el lucro cesante como "utilidad dejada de percibir"; Alberto Rey de Castro refiere al lucro frustrado como aquel beneficio que le ha sido privado a la víctima como consecuencia, por ejemplo, de un incumplimiento de contrato; Fernando De Trazegnies señala que "[e]l concepto de lucro cesante comprende aquello que ha sido o será dejado de ganar a causa del acto dañino", siendo que más adelante precisa que el lucro cesante se refiere al "margen de ganancia (no al ingreso bruto)" (p. 38) o a la "renta efectiva" (p. 41); Lizardo Taboada señala 
En otros términos, el lucro cesante no es equiparable a un "ingreso cesante", interpretación que tiene un sustento histórico (Rodrigo, 2003, pp. 641-652); sino que es el resultado de la liquidación a realizarse entre el ingreso esperado dejado de percibir y los costes (fijos y variables) necesarios para poder obtener dichos ingresos dentro de un horizonte de tiempo determinado. Lo cual, además, en el caso de lucros cesantes pasados deberá ser adecuadamente actualizado para obtener el valor del presente del mismo.

De este modo, para el caso de un trabajador que es despedido incausada o fraudulentamente, el ingreso esperado dejado de percibir sería la remuneración mensual, Sin embargo, para obtener el lucro cesante, a dichos ingresos se le deben deducir los costos correspondientes, por ejemplo, a la alimentación, transporte, entre otros en los que incurra el trabajador de forma mensual, siendo que el horizonte de tiempo estaría dado por el período existente entre el momento en que se produjo el despido y aquel en el que se realizó la reposición del trabajador a su puesto de labores. Evidentemente, la remuneración dejada de percibir no puede ser equiparada con el lucro cesante. Por ello, coincido con que se haya presidado de manera técnica y clara sobre el lucro cesante que:

Conviene precisar finalmente que el lucro cesante es equivalente a las presumibles ausencias de flujos de caja (estimadas, entonces, sobre la base de su probabilidad). Para su estimación serán utilizables todas las consecuencias disponibles al momento del proceso; si relativos al futuro, su valor esperado deberá ser actualizado a una tasa que tenga en cuenta el rendimiento esperado del dinero y de la compensación por el riesgo. (Trimarchi, 2010, p. 112)
Ahora bien; no obstante el grueso error conceptual en el se ha incurrido en el V Pleno, es auspiciable que la propia Corte Suprema, en cierta medida, lo haya enmendado en pronunciamientos posteriores, ya que ha expresado ${ }^{23}$ la diferencia que debe establecerse entre las remuneraciones devengadas y el lucro cesante en los siguientes términos:

(...) el lucro cesante y las remuneraciones devengadas tienen una naturaleza jurídica distinta, pues mientras el primero es una forma de daño patrimonial que consiste en la pérdida de una ganancia legítima o de una utilidad económica como consecuencia del daño; la segunda son las remuneraciones o ingresos que el trabajador no pudo cobrar por falta de contraprestación respecto de un trabajo efectivo, cuya naturaleza es retributiva y no indemnizatoria. Esos conceptos son entonces diferentes y la cuantía del último debe responder en su establecimiento a los criterios que establece el Código Civil (Casación Laboral 10934-2016-Tacna, del 19 de julio de 2018).

Lamentablemente, la confusión existente alrededor de la noción de lucro cesante y su vinculación con la remuneración devengadas como consecuencia de un despido incausado o fraudulento aún persiste. Para ello basta con apreciar el acuerdo plenario acordado por mayoría en el Pleno Jurisdiccional Nacional Laboral y Procesal Laboral ${ }^{24}$, Ilevado a cabo en la ciudad de Tacna los días 23 y 24 de mayo de 2019, con relación al primer subtema ("otorgamiento y cálculo del lucro cesante en caso de despido") del tema 1 ("otorgamiento y cálculo del lucro cesante y daño moral en caso de despido"), en el cual, si bien se afirma que el lucro cesante no es equivalente a las remuneraciones devengadas, se insiste en señalar que el lucro cesante debe ser entendido como todos los ingresos dejados de percibir. Aunque se

que el lucro cesante es "la renta o ganancia frustrada o dejada de percibir"; Juan Espinoza precisa que "[l]ucro cesante: Se manifiesta por el no incremento en el patrimonio del dañado (sea por incumplimiento de un contrato o por un acto ilícito). Es la ganancia patrimonial neta dejada de percibir por el dañado"; Leysser León establece con toda claridad la diferenciación entre lucro e ingreso: "Lucro", como es evidente, no equivale a "ingreso". El "lucro" es el ingreso menos los gastos. Los gastos a los que nos referimos son aquellos que se requiere abonar, precisamente, para mantener la fuente del ingreso y para producir el ingreso. "Lucro" es sinónimo de "rédito" o "utilidad". Si se resarce con el "ingreso", se incurre en el error de considerar que dicho "ingreso" se produce inevitableente para el damnificado, sin necesidad de que éste contribuya a generarlo (mediante su trabajo, por ejemplo)(p. 301).

23 El pronunciamiento corresponde a los señores magistrados supremos Arévalo Vela; De La Rosa Bedriñana, Yrivarren Fallaque, Yaya Zumaeta y Malca Guaylupo.

24 Sobre el particular se debe tomar en consideración que el Pleno Jurisdiccional Nacional Laboral y Procesal Laboral, si bien se realizó al amparo del artículo 116 del Texto Único Ordenado de la Ley Orgánica del Poder Judicial (a diferencia del V Pleno) no fue realizado a nivel de la Corte Suprema, sino de las Cortes Superiores de Justicia. En específico participaron 94 jueces superiores de las treinta y cuatro Cortes Superiores de Justicia. Esta precisión es importante, ya que si bien el Pleno Jurisdiccional de Tacna es posterior al V Pleno, de ninguna manera puede considerarse que estamos ante la superación del criterio establecido este último. No solo porque los autores de cada Pleno pertenecen a instancias diferentes, sino también porque los plenos jurisdiccionales no tienen valor normativo vinculante alguno. A lo sumo podría afirmarse que el Pleno de Tacna (2019) implicó un cambio de criterio con relación al Pleno de Chiclayo (2018). 
admite la posibilidad de realizar deducciones de otros ingresos o gastos, en ninguna parte se alude a la noción de utilidad o ganancia como concepto tipificador del lucro cesante.

En específico, en el referido Pleno Jurisdiccional se ha señalado lo siguiente:

En las pretensiones indemnizatorias derivadas de un despido inconstitucional, incausado o fraudulento declarados judicialmente como tales; el daño patrimonial invocado a título de lucro cesante debe ser entendido como todos los ingresos dejados de percibir como consecuencia directa e inmediata del despido y no como las remuneraciones dejadas de percibir; y cuya existencia real y objetiva deberán ser acreditadas a fin de determinar la cuantificación que se sustentará en un parámetro temporal referido al tiempo de duración del cese; un parámetro cuantitativo referido al importe de los ingresos ciertos que hubiera dejado de percibir; y cualquier otra circunstancia que tuviera incidencia directa en dicha cuantificación deduciéndose los ingresos que hubiese obtenido el demandante por servicios realizados en dicho período de cese y los gastos que hubiera efectuado en el caso de continuar laborando, para la obtención de sus remuneraciones (Acuerdo Plenario, 2016)

De esta forma, no es correcto considerar como monto íntegro del daño, a la cuantificación de las remuneraciones devengadas no pagadas, ya que, si bien es claro que el trabajador se ve perjudicado al verse impedido de percibir la remuneración establecida contractualmente, el verdadero problema es determinar si el daño (como efecto económico perjudicial) que sufre el trabajador, es equivalente a las remuneraciones dejadas de percibir. Esto es, si es posible, a nivel de liquidación del daño, equiparar el perjuicio económico (lucro cesante) con las remuneraciones devengadas.

Los ingresos dejados de percibir son, sin duda, un criterio para determinar la afectación en el patrimonio de la víctima, como se afirma en el Pleno de Tacna, pero de ahí a equipararlos al íntegro de dicha afectación, como se sostiene en el V Pleno, hay un salto lógico, imposible de ser salvado desde la una perspectiva legal ni operativa, de la tutela resarcitoria, tal como se verá a continuación.

B. Las remuneraciones devengadas no constituyen el lucro cesante derivado del despido incausado y fraudulento: deslinde operativo.

El equiparar lucro cesante con el ingreso dejado de percibir afronta, por lo menos, dos problemas vinculados a la operatividad de la determinación de la obligación indemnizatoria.

Por un lado, un problema de causalidad material, previsto en el artículo 1321 del Código civil ${ }^{25}$. Con dicha postura (lucro=ingreso) se asume que los ingresos, necesariamente, habrían ingresado a favor de la víctima, dejando de lado el parámetro de normalidad (Visintini, 1999, pp. 258-263) existente en el análisis de la relación de causalidad material en responsabilidad contractual en el ordenamiento peruano.

Por otro lado, un problema de causalidad jurídica; ya que la extensión del daño resarcible en responsabilidad contractual, en lo que a su cuantía se refiere, se encuentra claramente delimitado por criterios tales como el de compensación de beneficios (compensatio lucri cum danno) (De Cupis, 1975, pp. 327-342; Visintini, 2015, pp. 291-297), previsto en el artículo 1321 del Código Civil, o el criterio de evitabilidad del daño (Visintini, 2015, pp. 265-273), previsto en el artículo 1327 del mismo Código ${ }^{26}$.

Dichos criterios impiden equiparar el lucro cesante al ingreso dejado de percibir; ya que, de hacerlo, se admitiría que el sujeto perjudicado conserve un incremento patrimonial eventualmente adquirido como consecuencia de la realización del daño (Torres Vera, 2015, pp. 76-85), o se estaría incentivando a que la víctima no asuma medidas de prevención destinadas a mitigar las consecuencias económicas perjudiciales del daño sufrido.

Así las cosas, comparto la posición de el sector de la doctrina civil peruana que se opone a la práctica laboral que consiste en considerar como lucro

25 Código Civil peruano.Artículo 1321.- Queda sujeto a la indemnización de daños y perjuicios quien no ejecuta sus obligaciones por dolo, culpa inexcusable o culpa leve.

El resarcimiento por la inejecución de la obligación o por su cumplimiento parcial, tardío o defectuoso, comprende tanto el daño emergente como el lucro cesante, en cuanto sean consecuencia inmediata y directa de tal inejecución.

Si la inejecución o el cumplimiento parcial, tardío o defectuoso de la obligación, obedecieran a culpa leve, el resarcimiento se limita al daño que podía preverse al tiempo en que ella fue contraída.

26 Código Civil peruano Artículo 1327.- El resarcimiento no se debe por los daños que el acreedor habría podido evitar usando la diligencia ordinaria, salvo pacto en contrario. 
cesante a las remuneraciones devengadas, en los siguientes términos:

Esta visión desdibujada e injusta del lucro cesante es la que sustenta decisiones judiciales más que cuestionables en el ámbito del derecho laboral, principalmente, cuando se concede resarcimientos a los trabajadores de acuerdo con valorizaciones que toman en cuenta, en lo atinente al lucro cesante, el ingreso dejado de percibir y no el rédito o utilidad, cuyo cálculo exige descontar todos los gastos necesarios para lograr ese ingreso, así como los ingresos provenientes de otras fuentes(León, 2016, pp. 60-61).

Claramente, es más sencillo calcular el lucro cesante cuando este se equipara a las remuneraciones dejadas de percibir, pero dicho facilismo no debe llevar al intérprete, y menos aún al juzgador, a obviar la aplicación de reglas jurídicas previstas expresamente en la legislación peruana (art. 1321 y 1327 del Código Civil.), ni a descuidarlos estándares de prevención en la relación agente-víctima, alentando con ello a comportamientos conformistas por parte del trabajador.

Por ello, coincido con aquella posición que, desde la perspectiva del derecho laboral, sostiene que a fin de determinar el lucro cesante se pueden recurir a los siguientes criterios: (i) períodos inimputables a las partes (huelgas) y duración razonable del proceso (retraso en la administración de los procesos); (ii) no utilización de medidas cautelares (como evidencia de la no urgencia de la pérdida patrimonial); (iii) particularidades del caso concreto y del afectado (edad, factores de empleabilidad o condiciones de reinserción laboral); e (iv) ingresos obtenidos (percepción de ingresos alternativos) (Ávalos Jara, 2018, pp. 138-142).

Tal como se acaba de evidenciar, no queda sino reafirmar nuestra discrepancia respecto de la posición asumida por la Corte Suprema en el V Pleno respecto a que el lucro cesante esté integrado por las remuneraciones dejadas de percibir. Estas son solo un criterio a tomar en consideración al momento de calcular el lucro cesante, por lo que se debe realizar una serie de descuentos, siendo inviable que se otorgue el íntegro de las remuneraciones devengas a título de lucro cesante que, de forma imprecisa, es la posición que se ha asumido en el Pleno de Tacna.

\section{PROPUESTA DE JUSTIFICACIÓN PARA LA NO APLICACIÓN DEL V PLENO LABORAL A CA- SOS CONCRETOS: LA TESIS DE LA MORA DEL ACREEDOR}

Ahora bien, ante la imposibilidad de considerar que la remuneración devengada sea calificada como lucro cesante, cabe cuestionarse si existe alguna vía interpretativa alterna que permita (i) otorgar el íntegro de las remuneraciones dejadas de percibir al trabajador con carácter contraprestativo en el despido incausado o fraudulento; $y$, al mismo tiempo, (ii) reconocer los aportes al sistema previsional del trabajador, evitando con ello un tratamiento diferenciado con el despido nulo.

Desde mi punto de vista, es posible reconocer que sobre la base de los hechos en los que se encuentra un trabajador despedido incausada o fraudulentamente, se presenta un supuesto legalmente previsto en el ordenamiento jurídico peruano: la mora del acreedor (tesis de la mora del acreedor) (Blancas Bustamante, 2013, pp. 434-435; Arce Ortiz, 2015, pp. 236-237).

De conformidad con lo establecido en el artículo 1338 del Código Civil, el acreedor incurre en mora cuando, sin motivo legítimo, se niega a aceptar la prestación ofrecida por el deudor o no cumple con practicar los actos necesarios para que este pueda ejecutar la obligación (Barchi Velaochaga, 2004, pp. 629-694; Espinoza Espinoza, 2016, p. 240).

Bien vistas las cosas, cuando el empleador se niega a aceptar la ejecución de la prestación de su trabajador, por ejemplo, cuando se le impide ingresar a su centro de labores, justificando dicha decisión en la realización de un despido (que a la postre será considerado como incausado o fraudulento), estamos ante un rechazo de la puesta a disposición de la prestación laboral; lo cual bien puede catalogarse como un rechazo que no reviste "motivo legítimo".

¿Por qué el reconocer que estamos ante una hipótesis de mora del acreedor es una vía alternativa para solucionar el problema generado en el $\checkmark$ Pleno relativo al pago de los aportes al sistema previsional?

Cuando se configura una hipótesis de mora del acreedor, una de las consecuencias que se genera es la de trasladar el riesgo al acreedor ante la imposibilidad de la prestación no imputable al deudor. Ello es así ya que la mora del acreedor tiene como objetivo la tutela del interés de cada una de las partes en no perder el derecho a la contraprestación (Cattaneo, 1964, p. 49). Por ello, se ha indicado respecto de las normas que regulan la mora del acreedor lo siguiente:

En efecto, cuando el acreedor está en mora, se pone a su cargo el riesgo de la cosa debida, por tanto, si la cosa perece sin culpa del deudor, éste tendrá igualmente derecho a la contraprestación. (...) En definitiva, afirman, con tales 
normas la ley no entiende procurar al deudor un bien, ni el resultado de una actividad ajena, pretende sólo regular el nexo sinalagmático entre las dos prestaciones. Por tanto, la cooperación no es debida, se puede sólo sostener que su falta es considerada por el legislador como criterio para asignar al acreedor el riesgo que envuelven los obstáculos que puedan impedir la prestación del deudor(San Martín, 2011, p. 293).

Dicha consecuencia (la transferencia del riesgo) encuentra su justificación en el ordenamiento peruano en el artículo 1340 del Código Civil ${ }^{27}$, en el que se establece que los riesgos por la imposibilidad de cumplimiento de la obligación le corresponden al acreedor, salvo que obedezca a dolo o culpa inexcusable del deudor. Así, se ha precisado lo siguiente:

De acuerdo a nuestro ordenamiento jurídico, el riesgo de la contraprestación corresponde, en principio, al deudor (periculum est debitoris). Eso significa que si la prestación debida a cargo del deudor se hace imposible sobrevinientemente sin culpa de las partes, aquél pierde el derecho a la contraprestación.

De ser así, desde el momento en que el acreedor queda constituido en mora el riesgo se traslada a éste; así, si la prestación se torna imposible estando el acreedor en mora, éste deberá ejecutar la prestación a su cargo a pesar que la prestación que debía recibir se ha tornado imposible (Barchi Velaochaga, 2004, p. 681).

Lo anterior, trasladado a la hipótesis de despido incausado o fraudulento, implica que el empleador (acreedor de la prestación laboral), quien ya asumió el riesgo de la prestación de trabajo o actividad laborativa propio de la subordinación por la que se caracteriza la relación laboral (Neves, 2009, pp. 39-40), asuma también el riesgo de la imposibilidad de la prestación (la prestación laboral que se tendría que haber ejecutado durante el tiempo transcurrido entre el despido y la reposición devino en imposible materialmente de ser ejecutada). Ello determina que tenga que pagar la contraprestación a su cargo (todas las remuneraciones devengadas) como consecuencia del traslado del riesgo en virtud de la mora del acreedor.

Nótese que la mora del acreedor no se encuentra estructuralmente ligada al despido nulo en los términos a los que se refiere el legislador peruano, sino al rechazo sin motivo legítimo de la ejecución de la prestación. En ese sentido, tanto en el despido nulo, como en el incausado y el fraudulento, se presenta dicho motivo ilegítimo desde el momento en el que se considera que el mismo no es un despido permitido por el ordenamiento.

De este modo, la tesis de la mora del acreedor, ante la tesis de la ficción legal y la tesis de los efectos retroactivos del acto ineficaz, tiene las siguientes ventajas comparativas respecto de las otras dos aproximaciones:

(i) El trabajador recibe el íntegro de las remuneraciones devengadas, las cuales no se pagan a título de indemnización, sino que tienen naturaleza contraprestativa. Esto no implica la contravención a ninguna ficción legal, ya que su sustento se encuentra en la mora del empleador.

(ii) La no prestación efectiva de trabajo por parte del trabajador no impide reconocer naturaleza contraprestativa a las remuneraciones devengadas, ya que dicha característica se justifica en la traslación del riesgo derivada de la mora del empleador y no en la eficacia retroactiva de los actos de despido ineficaces.

(iii) Al considerar que las remuneraciones devengadas tienen naturaleza crontraprestativa, se habilita el pago de los aportes al sistema previsional, tal como sucede en el despido nulo, evitando con ello crear una situación de diferenciación arbitraria entre las modalidades de despido y evita la necesidad de crear un expediente retórico que afecte el sistema de indemnizaciones previsto legalmente.

Tal como se acaba de apreciar, la Corte Suprema pudo haber recurrido a la tesis de la mora del acreedor como alternativa de solución frente al problema denunciado. No obstante, ello no impide que los magistrados que atiendan a este tipo de problemática laboral puedan aplicar la alternativa de solución propuesta y, como consecuencia de ello, otorgar una adecuada tutela de intereses a los trabajadores despedidos de forma incausada o fraudulenta, en armonía con la regulación de la indemnización y del despido en el sistema peruano.

\section{CONCLUSIONES}

En función a lo expuesto a lo largo del presente artículo he arribado a las siguientes conclusiones:

1. La Corte Suprema ha tomado partido por la tesis de la ficción legal, según la cual las remuneraciones dejadas de percibir en el

27 Código Civil peruano. Artículo 1340.- El acreedor en mora asume los riesgos por la imposibilidad de cumplimiento de la obligación, salvo que obedezca a dolo o culpa inexcusable del deudor. 
despido nulo se justifican en una ficción creada por el legislador respecto de la prestación laborativa del trabajador, por lo que no puede extenderse dicha consecuencia a los despidos incausados o fraudulentos, ya que respecto de estos no media disposición normativa alguna.

2. Se ha descartado la tesis de los efectos retroactivos del acto ineficaz sin mayor justificación, con lo que no se ha podido reconocer naturaleza reinegrativa a la remuneración dejada de percibir, a pesar de que, tanto en el despido incausado como en el fraudulento, se configuran supuestos de nulidad material, pues en ambos se lesionan derechos constitucionales.

3. La Corte Suprema ha incurrido en un equívoco al considerar que las remuneraciones dejadas de percibir en los despidos incausados o fraudulentos tienen naturaleza indemnizatoria a título de lucro cesante; ya que no ha tomado en consideración que lo que se indemniza bajo este concepto de daño es la utilidad esperada y no el ingreso dejado de percibir.

4. El Pleno Jurisdiccional realizado en Tacna en el año 2019, si bien diferenció el lucro cesante de la remuneración devengada, insiste en definir el primero en función de la noción de ingreso cesante $y$, aunque admite la posiblidad de realizar deducciones en función de ingresos alternativo o gastos, en ningún momento se alude a la noción de ganancia o utilidad como parámetro para establecer el real alcance del lucro cesante.

5. La referencia al "daño punitivo" (sic) que realiza la Corte Suprema en el V Pleno ha sido únicamente un expediente retórico para reconocerle al trabajador, de algún modo, los aportes que pudieron realizarse al sistema de pensiones, pero que no podrían otorgarse al haberle negado carácter contraprestativo a las remuneraciones dejadas de percibir y haber optado por fijar su naturaleza indemnizatoria.

6. La solución adoptada por la Corte Suprema contraviene el principio de separación de poderes al haber creado una indemnización punitiva sin habilitación legal expresa para ello. Además, establece una diferenciación arbitraria entre el despido incausado o fraudulento y el despido nulo afectando la sostenibilidad del sistema previsional público.
7. Adoptar la tesis de la mora del acreedor supone una alternativa de solución, ya que con esta se niega carácter indemnizatorio a la remuneración dejada de percibir, reconociéndosele naturaleza contraprestativa, en virtud de la transferencia del riesgo producida por la mora, con lo cual deviene en innecesaria cualquier referencia al "daño punitivo" para justificar el aporte al sistema de pensiones del trabajador.

\section{REFERENCIAS}

Abanto Revilla, C. y J. Paitán Martínez (2017). ¿Dónde existe una cuantificación del monto de los daños punitivos ante el despido existen aportes previsionales pendientes de cobrar?. En: Diálogo con la jurisprudencia 228, pp. 33-48.

Abanto Revilla, C. (octubre de 2004). La crisis de los regímenes de pensiones administrados por el Estado y el futuro de la Seguridad Social en el Perú. Sociedad Peruana de Derecho del Trabajo y de la Seguridad Social: Desafíos y perspectivas del Derecho del Trabajo y de los regímenes de pensiones en el Perú. Congreso llevado a cabo en Trujillo.

Arce Ortiz, E. (2008). Derecho individual del trabajo en el Perú. Desafíos y deficiencias. Lima: Palestra.

(2015) La nulidad del despido lesivo de derechos constitucionales. Lima: Ubi Lex Asesores.

Ávalos Jara, O.V. (octubre de 2018). Límites razonables al uso desmedido del lucro cesante en materia laboral para los casos de despidos injustificados. En: VIII Congreso Nacional de Derecho del Trabajo y de la Seguridad Social. Congreso llevado a cabo en Chiclayo.

Barchi Velaochaga, L. - ¿Mora del acreedor? Necesidad de algunas precisiones. En: Escobar Rozas, F. (ed.) (2004). Negocio jurídico y responsabilidad civil. Estudios en memoria del profesor Lizardo Taboada Córdova. Lima: Grijley.

Bardales Siguas, L. (2017). Un intento fallido de trasplante legal: los punitive damages por despido arbitrario. En: Gaceta Ccivil \& Procesal Civil, Registral y Notarial 52, pp. 291-404.

Benatti, F. (2017). I danni punitivi nel panorama attuale. Giustizia Civile. Disponible en: http:// giustiziacivile.com/danno-e-responsabilita/ approfondimenti/i-danni-punitivi-nel-panorama-attuale 
Blancas Bustamente, C. (2013). El despido en el derecho laboral peruano. Tercera edición. Lima: Jurista.

Campos García, H. (2019). La (ilegítima) admisión de la indemnización punitiva en el ordenamiento peruano. En: Anales de Legislación Argentina 6.

Cattaneo, G. (1964). La cooperazione del creditore all'adempimento. Milán: Giuffré.

De Cupis, A. (1975). El daño. Teoría general de la responsabilidad civil. Segunda edición. Barcelona: Bosch.

De Trazegnies Granda, F. (1990). La responsabilidad extracontractual. Biblioteca para leer el Código Civil, volumen IV, tomo II. Lima: Fondo Editorial de la Pontificia Universidad Católica del Perú.

Espinoza Espinoza, J. (2016). Derecho de la responsabilidad civil. Lima: Instituto Pacífico.

(2016). La mora. En: THËMIS-Revista de Derecho 68 .

Fernández Cruz, G. (2001). Las transformaciones funcionales en la responsabilidad civil: la óptica sistémica. Análisis de las funciones de incentivación o desincentivación y preventiva de la responsabilidad civil en los sistemas del civil law. En: León Hilario, L. (ed.). Estudios sobre la responsabilidad civil. Lima: ARA.

(2017). La dimensión omnicomprensiva del daño no patrimonial y la reclasificación de los daños. En: Espinoza Espinoza, J. (dir.). Daño corporal. Nuevas orientaciones en la experiencia jurídica francesa y peruana. Lima: Instituto Pacífico.

Ferro Delgado, V. (1998). El concepto de remuneración. En: Asesoría Laboral 5, pp.11-17.

García Long, S. (2018). Daños punitivos en Perú. En: Actualidad jurídica Uría Menéndez 50, pp. 162-165.

Gorgiades, G. (2005), Punitive damages in Europe and the USA: doctrinal differences and practical convergence. En: Revue Hellenique de Droit International 58.

Gonzales Hunt, C. (2013). 25 años de la seguridad social en pensiones en el Perú. En: De los Heros Pérez-Albela, A. (coord.). Homenaje aniversario de la SPDTSS. Lima: Sociedad Peruana de Derecho del Trabajo y de la Seguridad Social.
Gonzales Hunt, C. y J. Paitán Martínez (2017). El derecho a la seguridad social. Lima: Fondo Editorial de la Pontificia Universidad Católica del Perú.

González Nieve, O. (octubre de 2004). Futuro de los regímenes pensionarios en Perú. Sistema estatal de pensiones. I Congreso de la Sociedad Peruana de Derecho del Trabajo y de la Seguridad Social: Desafíos y perspectivas del Derecho del Trabajo y de los regímenes de pensiones en el Perú. Congreso llevado a cabo en Lima.

Gotanda, J.Y. (2004). Punitive damages: a comparative analysis. En: Columbia Journal of Transnational Law 42.

Grondona, M. (2017) II problema dei danni punitive e la funzioni degli istituti giuridici, ovvero: il giurista e la politica del diritto. En GiustiziaCivile.com. Disponible en: http://giustiziacivile. com/danno-e-responsabilita/approfondimenti/il-problema-dei-danni-punitivi-e-la-funzione-degli-istituti

Koziol, H. (2008). Punitive damages - A european perspectives. En: Lousiana Law Review 68.

León Hilario, L. (2006). Derecho a la intimidad y responsabilidad civil. El refuerzo de los derechos fundamentales a través de remedios civilísticos. Lima: Facultad de Derecho de la Pontificia Universidad Católica del Perú.

(2016). Responsabilidad civil contractual y extracontractual. Material autoinstructivo. Lima: Academia de la Magistratura.

Neves Mujica, J. (1993). Sistema Nacional de Pensiones y Sistema Privado de Pensiones: opción diabólica. En: THĒMIS-Revista de Derecho 25.

(2009). Introducción al derecho del trabajo. Segunda edición. Lima: Fondo Editorial de la Pontifica Universidad Católica del Perú.

(2015). El despido en la legislación y en la jurisprudencia del Tribunal Constitucional y los Plenos Jurisprudenciales Supremos en materia laboral. En: THËMIS-Revista de Derecho 67.

Osterling Parodi, F. (1968). La valuación judicial de los daños y perjuicios. En: THEMIS-Revista de derecho 26.

Polinsky, A.M. y S. Shavell (2000). Punitive damages. En Encyclopedia of Law and Economics: civil law and economics, volumen II. Cheltenham: Edward Elgar. 
Pizarro Díaz, M. (2006). La remuneración en el Perú. Análisis jurídico laboral. Lima: Gonzales \& Asociados .

Quispe Montesinos, C.A. (2006). El pago de las remuneraciones devengadas como consecuencia de la reposición ordenada en un proceso de amparo. En: Foro Jurídico 6.

Rey de Castro, A. (1972). La responsabilidad civil extracontractual. Estudio teórico práctico del Derecho nacional y comparado. Lima: Universidad Nacional Mayor de San Marcos.

Rodrigo Alarcón, A. (2003). Evolución histórica de la figura del lucro cesante. En: Anuario da Facultade de Dereito da Universidade da Coruña 7.

Rojas Rojas, J. (2014). El sistema privado de pensiones en el Perú. Lima: Fondo Editorial de la Pontificia Universidad Católica del Perú.

San Martín Neira, L. (2011). Sobre la naturaleza jurídica de la 'cooperación' del acreedor al cumplimiento de la obligación. La posición dinámica del acreedor en la relación obligatoria, como sujeto no sólo de derechos, sino también de cargas y deberes. En: Revista de Derecho Privado 21, pp. 273-325.

Taboada Córdova, L. (2013). Elementos de la responsabilidad civil. Comentarios a las normas dedicadas por el Código Civil a la responsabilidad contractual y extracontractual. Lima: Grijley.

Tapia Gutiérrez, P. (2013). La reparación del daño en forma específica. El puesto que ocupa entre los medios de tutela del perjudicado. Madrid: Dykinson.

Toledo Toribio, O. (2014). Tratamiento judicial del despido incausado y despido fraudulento, y la problemática de la competencia del Juzgado de Paz Letrado, al influjo del II Pleno Jurisdiccional Supremos en materia laboral 2014. En: Soluciones Laborales 83, pp. 58-72.

(15 de mayo de 2012). "Reposición por despido incausado y fraudulento". En: Jurídica. Suplemento de Análisis Legal (suplemento de diario El Peruano).

Torres Vera, G. (2015). La indemnización frente a la nulidad del despido. Especial referencia a los trabajadores amparados por la Ley 24041 (tesis para optar el grado de bachiller en Derecho). Piura: Universidad de Piura.
Toyama Miyagusuku, J. (2000). La calificación de los ingresos del trabajador ¿cuáles son los criterios que deben seguirse? En: Ius et Veritas 20.

Toyama Miyagusuku, J. y C. Neyra Salazar (2016). Criterios jurisprudenciales de la Corte Suprema sobre el despido nulo. En: lus et Veritas 52.

Trimarchi, P. (2010). I/ contratto: inadempimento e rimedi. Milán: Giufrré.

Vinatea Recoba, L. (1994). La impugnación del despido en la Ley de Fomento del Empleo. En: THËMIS-Revista de Derecho 27-28.

Visintini, G. (1999). El daño. Otros criterios de imputación. En: Tratado de la responsabilidad civi, tomo II. Traducción de A. Kemelmajer de Carlucci. Buenos Aires: Astrea.

(2015). ¿Qué es la responsabilidad civil? Fundamentos de la disciplina de los hechos ilícitos y del incumplimiento contractual. Traducción de M. Cellurale. Bogotá: Universidad Externado de Colombia.

Zipursky, B. (2005). Theory of punitive damages. En: Texas Law Review 84

\section{LEGISLACIÓN, JURISPRUDENCIA Y OTROS DOCU- MENTOS LEGALES}

Decreto Legislativo 295. Código Civil peruano. En: Diario El Peruano, 25 de julio de 1984.

Texto Único Ordenado del Decreto Legislativo 728. Ley de Productividad y Competitividad Laboral. En: Diario El Peruano, 27 de marzo de 1997.

Decreto Supremo 017-93-JUS. Texto Único Ordenado de la Ley Orgánica del Poder Judicial de Perú. En: Diario El Peruano, 3 de junio de 1993.

Primer Pleno Jurisdiccional Laboral de la Corte Suprema de Justicia, del 4 y 14 de mayo de 2012.

Quinto Pleno Jurisdiccional Laboral de la Corte Suprema de Justicia, del 19 de octubre de 2016.

Pleno Jurisdiccional Nacional Laboral y Procesal Laboral (Chicalyo), del 13 y 14 de setiembre de 2018.

Pleno Jurisdiccional Nacional Laboral y Procesal Laboral (Tacna), 23 y 24 de mayo de 2019.

Sentencia recaída en el Expediente 976-2001-AA/ TC, del 13 de marzo de 2003. 